Farzad, M.R., and Cameron, V.A. (2019). "Implementing Lean Visual Tools on The Closeout Phase of A Global-Scale Industrial Project." In: Proc. $27^{\text {th }}$ Annual Conference of the International. Group for Lean Construction (IGLC), Pasquire C. and Hamzeh F.R. (ed.), Dublin, Ireland, pp. 675-686. DOI: https://doi.org/10.24928/2019/0184. Available at: 〈www.iglc.net>

\title{
IMPLEMENTING LEAN VISUAL TOOLS ON THE CLOSEOUT PHASE OF A GLOBAL- SCALE INDUSTRIAL PROJECT
}

\author{
Mohammad Reza Farzad ${ }^{1}$, Vhybirt A. Cameron ${ }^{2}$
}

\begin{abstract}
The construction industry has long been struggling with issues such as safety, efficiency, and quality. Many tools and methods have been introduced to alleviate the current problems of this industry. Lean practices have been promising in recent years in the matter of improving project safety, communications and efficiency. However, these tools have mainly been implemented at the peak of a construction project's activities, where resources are at their highest levels, but seemed to be neglected at the ending phase of closeout. To study the effectiveness of lean practices in this phase, this paper has evaluated the utilization of visual management methods as a case study on a large-scale multi-phase, multi-cultural industrial project in Mexico. Hence, a visual matrix was developed after thorough analysis and continues improvement. Moreover, procedures were developed to use this tool to communicate, track and coordinate the closeout process. After the completion of the project, five milestone dates were extracted, and the information was compared against previous phase data. The result of the study shows that using this tool can decrease the duration of the closeout process, improve the communication between different stakeholders and aid to overcome challenges derived from differences in culture, methods, and expectations.
\end{abstract}

\section{KEYWORDS}

Lean Construction, Closeout, Visual Management, International, Multi-Culture.

\section{INTRODUCTION}

A construction project does not simply start and finish at the operation phase of the project. One of the important milestones which is usually defined in the construction contract is substantial completion. The American Institute of Architects (2007) has defined this document as "The stage in the progress of the Work when the Work or designated portion thereof is sufficiently complete in accordance with the Contract Documents so that the Owner can occupy or utilize the Work for its intended use". The process after this stage is labelled as the start of the closeout process. This closeout phase which can be referred as

1 VDC Engineer, Gilbane Building Company, 13750 San Pedro Ave., Ste. 550, San Antonio, TX 78232, USA, +1 571 216-6016, mfarzad@ gilbaneco.com

2 Project Manager, Gilbane Building Company, 13750 San Pedro Ave., Ste. 550, San Antonio, TX 78232, USA, +1 210 714-3641, vcameron@gilbaneco.com 
the final one percent of the project, is a complicated process that usually involves corrections and deliverable handovers to the client. This process is usually neglected in the primary planning of the project (Carson et al. 2009). Studies show that the mismanagement of project closeout not only can have direct financial impacts on the contractor due to contractual obligations but also can impact their relationship with the client for future business (Arditi et al. 2008). The result of the surveys conducted by Rogers (2012) demonstrate that most of the stakeholders believe other parties are to blame for the delay in the closeout process. In addition, studies also show that a lack of communication and motivation are important factors that create delays in the closeout process (Kaul 2014). Furthermore, studies show that communication is one of the key problems in the construction industry, especially in projects with employing minorities and diverse background groups. (Loosemore and Lee 2002).

Moreover, there are many studies that have been conducted on improving the communication by using different tools and methods. Among these, visual management as a lean tool is proven to improve the communication and decision making in managing processes (Koskela et al. 2018). This is especially evident on projects that have language barriers, as visual management has shown to facilitate the communication on jobsites to improve the health and safety of the workers (Bust et al. 2008). Although there are numerous studies utilizing visual management tools in different stages of construction, there are few evidences of using this tool in the closeout process of projects where communication is a challenge.

This study aims to evaluate the effectiveness of lean visual management tools in resolving the issues raised in the closeout stage of a construction project.

\section{LITERATURE REVIEW}

\section{LEAN ViSUAL TOOLS IN CONSTRUCTION}

Although visual management tools have been used in construction industry for a while as signs, color coding, and hazard elements, there is a large potential for implementation in managerial levels and site logistic improvement (Tezel et al. 2013). Tezel et al. (2015) have investigated the advantages of visual management as a "managerial strategy" which can benefit a project in aspects such as transparency, ease of information flow and minimizing complication in communication. The study has suggested a pathway for effective implementation of this process. Furthermore, other studies have been conducted on the benefits of using visual tools to improve construction safety, sustainability and information transparency. (Bae and Kim 2008; Valente and Costa 2014; Bust et al. 2008).

Some researchers have integrated Building Information Modeling (BIM) tools with visual management to improve the efficiency and communication in construction projects. Sacks el al. (2009) study shows using visual tools in daily construction work integrated with 3D representation of the jobsite has improved communication, organization, accessibility and facilitates the distribution of information to project members at different levels of management. In addition, Laine et al. (2014) has developed a 3D model-based system to improve information management in a construction project in Finland. The result of the study has suggested a reduction in the duration and waste of several activities. 
Furthermore, BIM based visual management tools have reduced communication and decision-making time in a healthcare project in Chile which had minimized delays that are typical for this type of project (Matta et al. 2018).

Lean visual tools have been utilized in large scale international projects to overcome their complex issues. Studies such as Barbosa et al. (2013) have evaluated the implementation of lean visual tools in a large-scale construction company in Brazil which has proven improvement in safety, teamwork and communication. Furthermore, Tezel and Aziz (2017) have suggested that integration of information technology and visual management can be beneficial for the construction and post construction phases of a largescale project.

Recently, more companies around the world are taking advantage of lean practices and specifically, visual management at different levels and departments in the construction industry (Brandalise et al. 2018; Tezel et al. 2011; Tezel et al. 2015). Despite this, none of these studies have shown the use of visual management tools in the closeout phase of the construction project. Most of the studies have mainly focused on the execution of the work, which is the peak of the bell curve for a construction project's lifecycle, where project activities and manpower are typically at their highest. The final stage which is crucial for the future of different stakeholders involved in a large-scale project is most times neglected. (Carson et al. 2009).

\section{RESEARCH METHOD}

\section{Case Study}

The study was conducted on an international industrial construction project in Mexico. This project was established in multi-phases; each phase with similar scope and characteristics. The significance of this project was the presence of stakeholders with multiple nationalities and backgrounds. Hence, this case study could investigate using lean visual tools in a project with cultural differences which has not been thoroughly evaluated by other researchers (Valente et al. 2016).

The goal of this study was to develop a visual management tool throughout the project by analysing the root causes of existing issues and continuous improvement to reach a level which the tool could be fully utilized. Furthermore, to investigate the effectiveness of using lean visual tool in the closeout process, a comparison was conducted between two distinct phases that were constructed by multiple contractors in this project. The first phase (phase 1) was constructed during years 2014-2016. During this phase, the visual tool was under development and only implemented for selected contractors for further development. Consequently, the tool was employed project-wide for phase two and it was shared with contractors and the client. Phase 2 was started on 2016 and completed on 2018.

\section{DEVELOPMENT OF THE VISUAL MANAGEMENT MATRIX}

To determine the suitable tools and methods for this project an evaluation was conducted. Analysing the causes of the various issues was determined by using the 5 why analysis (Figure 1). 


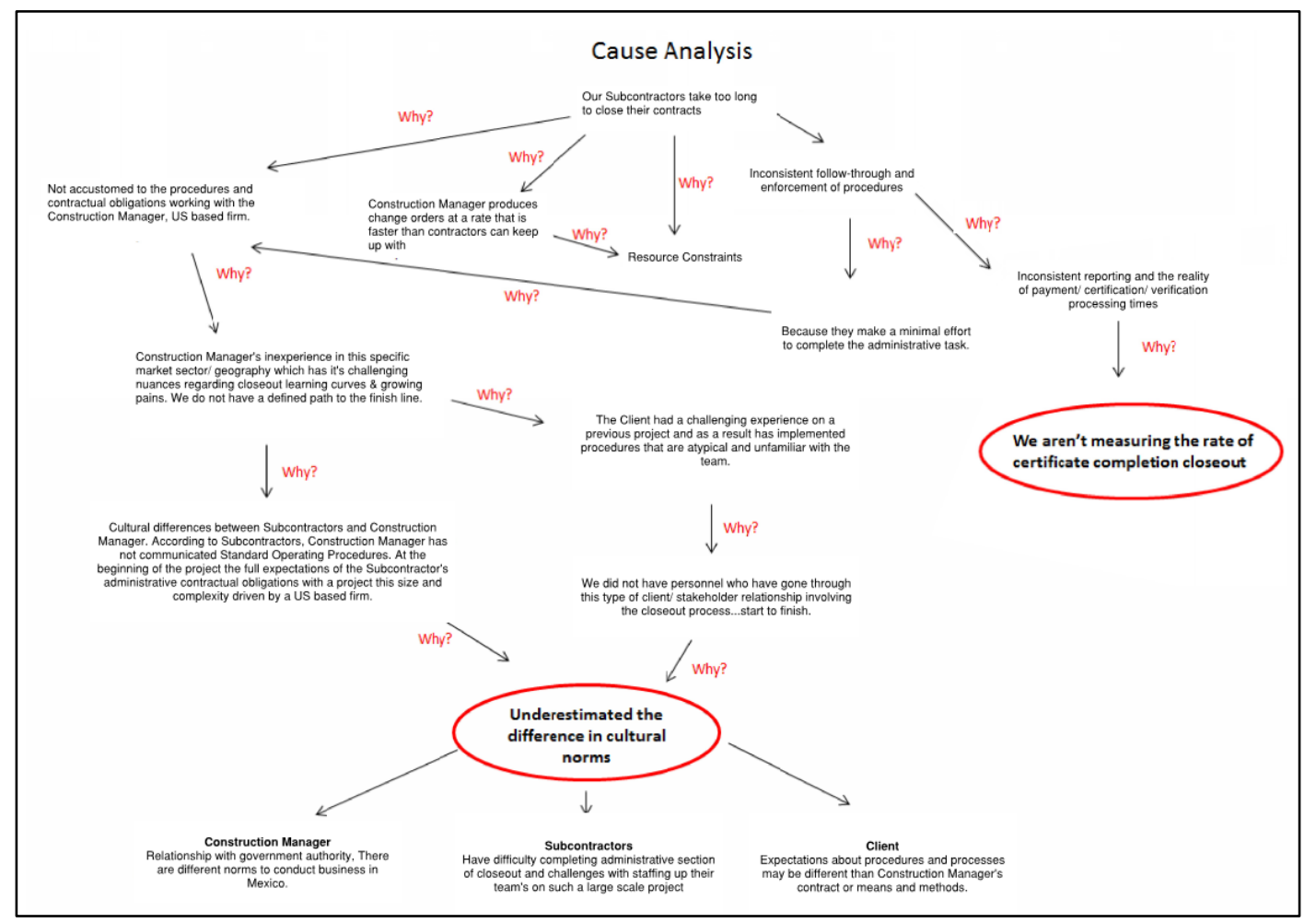

Figure 1: 5 Whys Analysis Conducted to Evaluate the Root Causes

The results showed that the difference in cultural norms and procedures were underestimated and there were inefficient standard procedures to track progress. Therefore, cultural differences caused difficulties in communication between different parties. To address this issue a visual tool (matrix) should have been designed to communicate to all project stakeholders, about the status of any given bid package and subcontractor throughout the construction phase which at the same time could track progress.

The initial efforts included extracting all the contractual deliverables and creating a sequence to clearly show how each phase and milestone flowed from beginning to end. The challenges faced by the project team were unique since a project of this size and scope had not been completed by anyone on the initial team before. Furthermore, other challenges included special Mexican federal requirements, team members with different procedural norms and the multi-cultural diversity of the stakeholders. The team utilized the company's typical final payment checklist which had general contractual items that would be verified before a subcontractor received their final payment, closing their contract (Figure 2). 


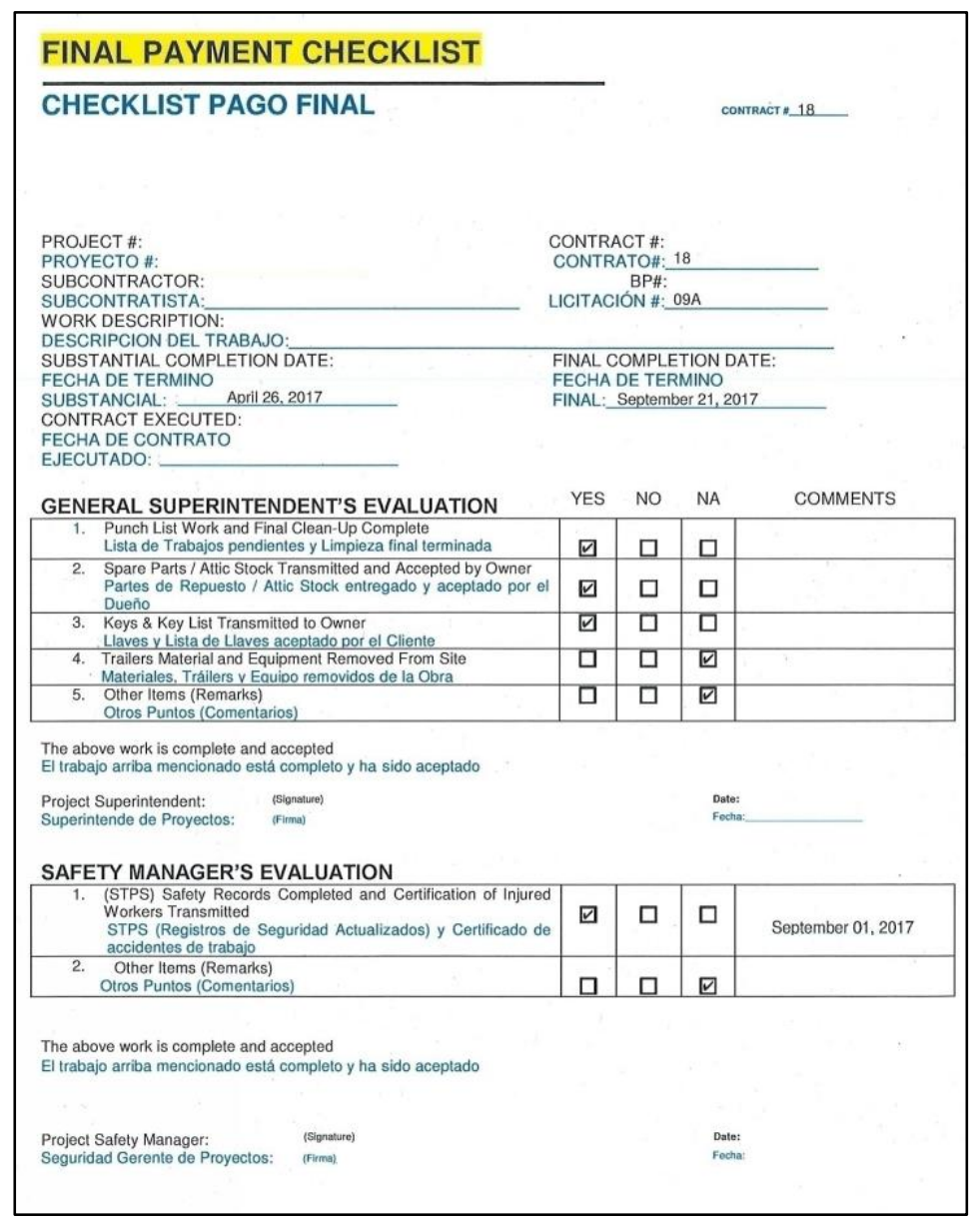

Figure 2: Standard Closeout Checklist Used in The Project to Document the Process

The checklist became the basis for the matrix items including the specific deliverables unique to this multi-phased project. The matrix deconstructed the final payment checklists and displayed them in a format whereby the phase of a project could easily be seen in its entirety.

The format of the matrix evolved throughout the life of the project based on continuous improvements and feedback from internal team members and the client. Colour was used as a visual tool to guide viewers to important aspects of the project and their status. Red was used to alert team members of items that required attention while contrasting circles highlighted changes from the last updated matrix. The matrix was updated on a weekly basis and reports were distributed among different stakeholders. In addition, the issue was tackled right away by making the topic of closeout a weekly agenda item with subcontractor staff meetings and reinforcing outstanding deliverables with a matrix printed on 48 inches by 60 inches and pasted on our wall (Figure 3). 


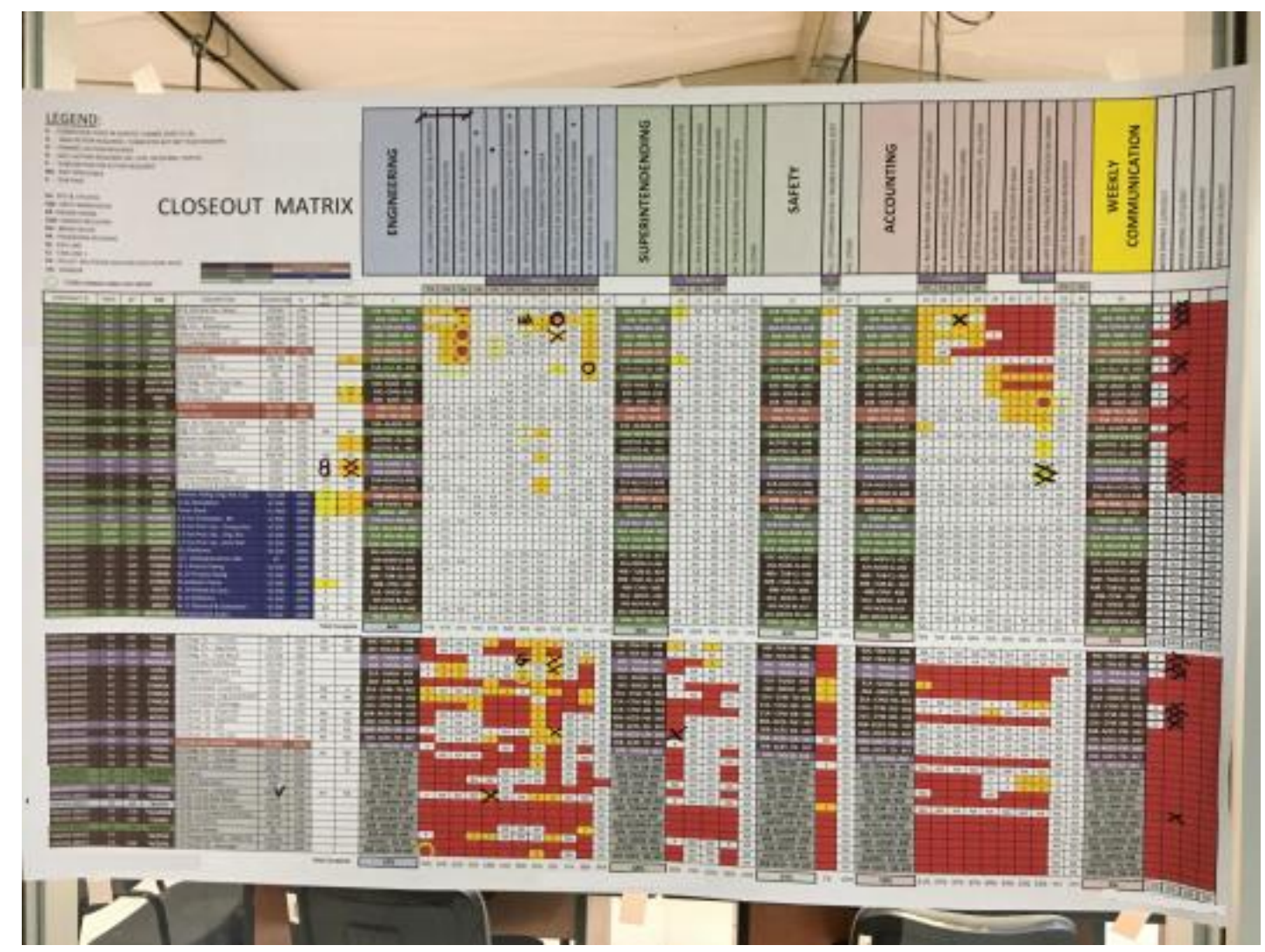

Figure 3: The Closeout Visual Tool Attached to The Office Wall

\section{Data Collection}

After the completion of phase 2, to conduct the comparison, data was extracted from closeout checklists of various contractors for phase 1 and 2 . The checklists recorded the date each step of closeout was performed, and when the closeout process was concluded. This checklist records various items as obligations for different stakeholders, however, there are five key milestones which drive the completion of the closeout phase. These items are defined as follows:

- Substantial Completion: As discussed previously, substantial completion is a standard term which defines the date when scope of work is completed, turned over and/or occupied by the client. This milestone is considered as the baseline of our data since the closeout stage starts after this event.

- Final Completion: Final Completion is not only a term and milestone but is also certified as a document executed by different stakeholders when all the punchlist and engineering document transmittals are completed. This milestone shows the time when all the construction activities of any type are concluded by the contractor.

- Safety Documentation (STPS): According to Mexican regulations, the companies are obligated to submit their safety documents to the authorities including but not limited to: incident reports, man power reports, certifications and safety plans. This 
report can be completed when all the construction activities are concluded, and series of reviews conducted by the construction manager and the client.

- Social Security Documentation (IMSS): Similar to safety documentation, contractors are obligated to submit their financial and man power documentation to the social security authorities in Mexico. When documents are submitted, the authorities will conduct reviews and determine the payment amount to be processed by the contractors. This process can take several months dependant on complexity and number of sub-subcontractors.

- Final Payment Request: When all the closeout items on the checklist are completed, the final payment request is submitted to the client to authorize the release of contractors' retentions for final payment. This milestone represents the last step of the closeout process.

To evaluate the effectiveness of a visual management approach, the above milestone dates were extracted from checklists that were completed for contractors in both phases. To quantify progress, substantial completion was set as the baseline and for the other 4 milestones, the number of days from substantial completion was calculated.

For this study, 10 contractors with different types and scopes of work were randomly selected from each phase and data were extracted from their closeout checklist. The data are presented as follows:

\section{DATA}

Table 1: Phase 1 Closeout Items (Number of Days from Substantial Completion)

\begin{tabular}{cccccc}
\hline $\begin{array}{c}\text { Subcontractors } \\
\text { Phase 1 }\end{array}$ & $\begin{array}{c}\text { Substantial } \\
\text { Completion }\end{array}$ & $\begin{array}{c}\text { Safety } \\
\text { Documentation }\end{array}$ & $\begin{array}{c}\text { Final } \\
\text { Completion }\end{array}$ & $\begin{array}{c}\text { Social Security } \\
\text { Documentation }\end{array}$ & $\begin{array}{c}\text { Final Pay } \\
\text { Request }\end{array}$ \\
\hline Contractor A & $9 / 21 / 2015$ & 554 & 564 & 618 & 623 \\
Contractor B & $9 / 21 / 2015$ & 234 & 525 & 891 & 892 \\
Contractor C & $2 / 26 / 2016$ & 165 & 471 & 529 & 599 \\
Contractor D & $6 / 22 / 2016$ & 49 & 181 & 398 & 482 \\
Contractor E & $8 / 9 / 2016$ & 128 & 133 & 331 & 345 \\
Contractor F & $7 / 22 / 2016$ & 244 & 285 & 277 & 290 \\
Contractor G & $8 / 12 / 2016$ & 235 & 406 & 361 & 447 \\
Contractor H & $6 / 8 / 2016$ & 162 & 272 & 292 & 302 \\
Contractor I & $10 / 6 / 2016$ & 247 & 196 & 259 & 287 \\
Contractor J & $9 / 21 / 2016$ & 229 & 239 & 782 & 813 \\
\hline
\end{tabular}


Table 2: Phase 2 Closeout Items (Number of Days from Substantial Completion)

\begin{tabular}{cccccc}
\hline $\begin{array}{c}\text { Subcontractors } \\
\text { Phase 2 }\end{array}$ & $\begin{array}{c}\text { Substantial } \\
\text { Completion }\end{array}$ & $\begin{array}{c}\text { Safety } \\
\text { Documentation }\end{array}$ & $\begin{array}{c}\text { Final } \\
\text { Completion }\end{array}$ & $\begin{array}{c}\text { Social Security } \\
\text { Documentation }\end{array}$ & $\begin{array}{c}\text { Final Pay } \\
\text { Request }\end{array}$ \\
\hline Contractor $\mathrm{A}^{*}$ & $7 / 18 / 2017$ & 128 & 144 & 173 & 391 \\
Contractor $\mathrm{B}^{*}$ & $2 / 6 / 2017$ & 52 & 91 & 142 & 164 \\
Contractor $\mathrm{C}^{*}$ & $11 / 14 / 2017$ & 5 & 30 & 247 & 251 \\
Contractor $\mathrm{D}^{*}$ & $5 / 22 / 2017$ & 3 & 47 & 78 & 133 \\
Contractor $\mathrm{E}^{*}$ & $8 / 7 / 2017$ & 34 & 241 & 450 & 458 \\
Contractor $\mathrm{F}^{*}$ & $2 / 2 / 2017$ & 61 & 95 & 187 & 242 \\
Contractor $\mathrm{G}^{*}$ & $2 / 6 / 2017$ & 32 & 91 & 150 & 164 \\
Contractor $\mathrm{H}^{*}$ & $2 / 6 / 2017$ & 100 & 100 & 101 & 119 \\
Contractor $\mathrm{I}^{*}$ & $2 / 6 / 2017$ & 38 & 142 & 386 & 387 \\
Contractor $\mathrm{J}^{*}$ & $6 / 6 / 2017$ & 37 & 77 & 231 & 251 \\
\hline
\end{tabular}

\section{DISCUSSION}

\section{Data Analysis}

Data extracted from the checklists for phase 1 has shown the average of 508 days for the closeout process whereas this number is reduced to 256 days for phase 2 which shows an overall 50\% reduction in contract closeout time. The largest improvement in this milestone concerned STPS with about 78\%. Moreover, the final completion milestone improved by about 68\%, and Social Security documents with about 55\% improvement. These results show that using the visual management tool assisted phase 2 closeout to be accomplished at a faster pace. However, factors such as lessons learned, improved experience and familiarity of the project team with the environment and culture should be considered. On the other hand, improvements in some of these milestones are related to the preceding milestones and do not necessarily show overall improvement in that specific process. For instance, most of the time spent on the IMSS process was not under the consortium team's control, however, completing the documentation and resolving the cost claims in a timely manner, helped to reduce the total duration for this process.

\section{GENERAL OBSERVATIONS}

The matrix gave the team a visual dashboard to gauge the status of closeout items. The matrix presence on a large size paper on the office wall increased the engagement of the project team as they would stop, look, take photos and notes, and ask questions to determine the outstanding items for the closeout process. In addition, the project engineers and project 
managers were using markers to update the matrix as they progressed on the closeout with a contractor.

Additionally, distributing the weekly report increased upper management's awareness of the progress by giving them a summary report of percentages complete for each area. On the first phase, in some cases, the closeout was mainly underestimated by the management team and usually the only tactic used to complete the process was terms such as "it should be done as soon as possible". In the second phase, by receiving visual reports like the closeout matrix, the management team focused more on the number of circles as they showed weekly progress and the size of the red cell mass on the matrix as this showed areas that needed more attention.

Using colors to visualize the closeout process, improved communication with contractors in their weekly meeting with the construction manager as they had a better understanding of where they were compared to other companies and what items were preventing them from receiving their final payment. Whereas, on the previous phase due to a lack of understanding and clear communication, the contractors would have seen the delay in the final payment mainly as the construction manager and client's fault.

Equally important, implementation of this tool did not solve all the issues regarding the closeout process and did not eliminate unnecessary delays to contractors' final payment. Complication of Mexican regulations and prolonged administrative processes caused major delays to final payments to contractors in both phases. Also, challenges like moving personnel with closeout experience out of the project and shortage in administrative manpower were still main issues.

\section{CONCLUSIONS}

The construction industry is a complicated area with unique problems for each individual project depending on its size, location, culture and duration. One of the biggest issues with almost any construction project phase are delays in the closeout process. The issues are proven to cause tension between various stakeholders which would have direct and indirect financial impact on their business. A few studies have been conducted that tried to determine the root causes and solutions to this problem, however, there are not many studies considering visual management tools which have been proven to have positive impacts on communication and decision making at the construction phase of a project.

This study assessed the implementation of lean visual management tools on a largescale multi-cultural construction project in Mexico to examine the effect of such tools on improving communication and cultural hindrances on the closeout phase of this project. The visual management tools were developed after conducting thorough analysis on the root causes of the issues and studying the current resources and tools that had been used on the project. Consequently, a matrix was created along with procedures to engage employees and track the progress for the closeout process.

To experiment with this tool, the updated matrix was fully implemented for the second phase of the project. In addition, to quantify the effectiveness of this process, data were extracted by randomly selecting contractors from the initial phase that were managed during the development phase of the matrix and the later phase which totally utilized the 
new visual management system. The result of the study demonstrated improvement in 4 major closeout milestones along with a 50\% reduction for the total duration of the process. In addition, the tool increased the engagement of employees, enhanced the levels of communication between all stakeholders, and improved the information quality for use of executive management.

To conclude, lean visual management is an effective tool to improve communication and overcome cultural differences in the closeout phase of large-scale construction projects. However, this tool alone cannot eliminate all issues associated with project closeout.

\section{REFERENCES}

Architects, American Institute of. (2007). Document A201 - General Conditions of the Contract for Discussion Substantial Completion.

Arditi, D., Polat, G., \& Makinde, S. A. (2008). Marketing practices of US contractors. Journal of Management in Engineering, 24(4), 255-264.

Bae, J. W., \& Kim, Y. W. (2008). Sustainable value on construction projects and lean construction. Journal of green building, 3(1), 156-167.

Barbosa, G., Andrade, F., Biotto, C., \& Mota, B. (2013). Implementing lean construction effectively in a year in a construction project. In Proceedings of the 21st Annual Conference of the International Group for Lean Construction (IGLC).

Brandalise, F.M.P. , Valente, C.P. , Viana, D.D. \& Formoso, C.T. 2018, 'Understanding the Effectiveness of Visual Management Best Practices in Construction Sites' In:, 26th Annual Conference of the International Group for Lean Construction. Chennai, India, 18-20 Jul 2018. pp 754-763

Bust, P. D., Gibb, A. G. F., and Pink, S. (2008). "Managing construction health and safety: Migrant workers and communicating safety messages." Saf. Sci., 46(4), 585-602.

Carson, C. W., Potter, J. C., Sanders, M. C., \& Stauffer, J. J. (2009). The Great Debate: Planning and Scheduling from Substantial to Final Completion. AACE International Transactions.

Kaul, V. (2014). Excessive delays in closeouts can be removed with the adaptation of better practices.

Koskela, L., Tezel, A. \& Tzortzopoulos, P. 2018, 'Why Visual Management?' In:, 26th Annual Conference of the International Group for Lean Construction. Chennai, India, 18-20 Jul 2018. pp 250-260

Laine, E. , Alhava, O. \& Kiviniemi, A. 2014, 'Improving Built-in Quality by Bim Based Visual Management ' In:, Kalsaas, B.T., Koskela, L. \& Saurin, T.A., 22nd Annual Conference of the International Group for Lean Construction. Oslo, Norway, 25-27 Jun 2014. pp 945-956

Loosemore, M., \& Lee, P. (2002). Communication problems with ethnic minorities in the construction industry. International Journal of Project Management, 20(7), 517-524.

Matta1, G. , Herrera, R.F. , Baladrón, C. , Giménez, Z. \& Alarcón, L.F. 2018, 'Using BIMBased Sheets as a Visual Management Tool for on-Site Instructions: A Case Study' In:, 26th Annual Conference of the International Group for Lean Construction.Chennai, India, 18-20 Jul 2018. pp 144-154 
Rogers, J. (2012). Opportunity Lost: Mismanagment of the Closeout Phase of Construction Projects.

Sacks, R., Treckmann, M., \& Rozenfeld, O. (2009). Visualization of work flow to support lean construction. Journal of Construction Engineering and Management, 135(12), 1307-1315.

Tezel, A., \& Aziz, Z. (2017). From conventional to IT based visual management: a conceptual discussion for lean construction. Journal of Information Technology in Construction (ITCon), 22, 220-246.

Tezel, A., Koskela, L., Tzortzopoulos, P., Formoso, C. T., \& Alves, T. (2015). Visual management in Brazilian construction companies: taxonomy and guidelines for implementation. Journal of management in engineering, 31(6), 05015001.

Tezel, B. A., Koskela, L. J., \& Tzortzopoulos Fazenda, P. (2013). Visual management in industrial construction: a case study.

Tezel, A., Koskela, L. , Tzortzopoulos, P. , Koskenvesa, A. \& Sahlstedt, S. 2011, 'An Examination of Visual Management on Finnish Construction Sites' In:, Rooke, J. \& Dave, B., 19th Annual Conference of the International Group for Lean Construction. Lima, Peru, 13-15 Jul 2011.

Valente, R. C., \& Costa, D. B. (2014). Recommendations for practical application of transparency in construction site. IGLC \& Akademika forlag, Norway.

Valente, C.P., Pivatto, M.P. \& Formoso, C.T. 2016, 'Visual Management: Preliminary Results of a Systematic Literature Review on Core Concepts and Principles' In, 24th Annual Conference of the International Group for Lean Construction. Boston, USA, 20-22 Jul 2016. 
Farzad, M.R., and Cameron, V.A

686

Proceedings IGLC - 27, July 2019, Dublin, Ireland 